\title{
Preliminary Study: Diseminasi Produk Dokumentasi Budaya Melalui Proyek Menara Ilmu Pusat Dokumentasi Budaya
}

\author{
Nindya Indrasweri ${ }^{1}$, Elya Riska Dwi Wahyuni ${ }^{2}$, M. Salman Al Farisy ${ }^{3}$ \\ ${ }^{1,2,3}$ Program Studi Diploma Tiga Kearsipan, Sekolah Vokasi Universitas Gadjah Mada
}

\begin{abstract}
This paper aims to describe efforts to disseminate cultural documentation products that have been collected by the Cultural Documentation Center through the Menara IImu portal. In the archival perspective, cultural documentation products are an important component for dissemination. The management of cultural documentation products is carried out through the Total Archives approach and the neo-documentation concept. In addition, this study also provides an alternative to the optimization of the dissemination of cultural documentation products through the Culture Documentation Tower Science Project (PDB UGM UGM). The data used in this paper consists of primary data and secondary data. Primary data were collected through non-participation observations by looking at the Menara Menara Pusat cultural documentation and questionnaires with random sampling. The questionnaire was distributed to 100 respondents through Google forms. The conclusion obtained, namely the optimization of dissemination of cultural products can be implemented through "show ads" publication with an internal and external partnership system ". Thus the existence of cultural documentation and archive products can be optimized and can be a promotional event in the field of archives with the concept of virtual exhibition in accordance with the digital era.
\end{abstract}

Submitted: 22/11/2019

Received: 22/01/2020

*Correspondence: Nindya Indrasweri nindyaindrasweri@mail.ugm.ac.id

KEYWORDS: documentation, culture, menara ilmu

\section{INTISARI}

Makalah ini bertujuan untuk mendeskripsikan upaya mendiseminasikan produk dokumentasi budaya yang telah dikumpulkan oleh Pusat Dokumentasi Budaya melalui portal Menara Ilmu. Dalam perspektif ilmu kearsipan, produk dokumentasi budaya menjadi salah satu komponen yang penting untuk didiseminasikan. Pengelolaan produk dokumentasi budaya dilakukan melalui pendekatan Total Archives dan konsep neo-dokumentasi. Selain itu, penelitian ini juga memberikan alternatif optimalisasi diseminasi produk dokumentasi budaya melalui Proyek Menara Ilmu Pusat Dokumentasi Budaya (PDB SV UGM). Data yang digunakan dalam makalah ini terdiri dari data primer dan data sekunder. Data primer dikumpulkan melalui observasi non-partisipasi dengan mencermati portal Menara Ilmu Pusat Dokumentasi budaya dan kuesioner dengan random sampling. Kuesioner disebar kepada 100 responden melalui google forms. Kesimpulan yang diperoleh, yaitu optimalisasi diseminasi produk budaya dapat diimplementasikan melalui "publikasi "show ads" dengan sistem partnership internal dan eksternal". Dengan demikian eksistensi produk dokumentasi budaya serta arsip dapat optimalkan serta dapat menjadi ajang promosi bidang kearsipan dengan konsep virtual exhibition sesuai dengan era digital.
KATA KUNCl:

dokumentasi, budaya, menara ilmu

CITE THIS ARTICLE: Indrasweri, N., Wahyuni, Elya, R. D., Al Farisy, M. Salman. (2019). Preliminary

Study: Diseminasi

Produk Dokumentasi

Budaya Melalui Proyek Menara Ilmu Pusat Dokumentasi Budaya. Jurnal Diplomatika, 3(1), 52-62. 


\section{PENDAHULUAN}

Budaya merupakan hasil cipta, karya, dan karsa manusia yang dituangkan dalam beragam aktivitas dan direkam dalam berbagai wujud media. Kegiatan merekam berbagai aktivitas kebudayaan lazim disebut sebagai dokumentasi. Oleh karena beragamnya budaya dan pendokumentasiannya, maka rupa produk dokumentasi yang dihasilkan pun beraneka ragam. Dalam proposal ini, produk dokumentasi budaya akan ditinjau dari sudut pandang ilmu kearsipan. Pada konteks Indonesia, arsip masih lekat dikaitkan dengan produk-produk administratif birokrasi, baik berupa kertas kerja, korespondensi, laporan, dan berbagai naskah dinas lain pendukung operasional suatu institusi resmi pemerintahan. Pandangan tersebut tidak lepas dari akar sejarah bangsa yang mengidentifikasi kearsipan sebagai tugas administratif dan hanya berlaku di lingkungan perkantoran. Padahal produk dokumentasi kebudayaan juga layak diistilahkan dengan arsip, dan pendokumentasian aktivitas kebudayaan pun tidak ada larangan untuk tidak menyebut dengan istilah pengarsipan budaya.

Paradigma pengarsipan budaya berkembang dari konsep total archives yang berkembang di Kanada. Konsep total archives muncul di Kanada sejak abad ke-19. Kemunculan konsep tersebut dilatarbelakangi oleh konteks sosial budaya, yaitu keyakinan dan kesadaran masyarakat Kanada untuk melestarikan dokumen yang merekam aktivitas sosial budaya dengan cakupan masyarakat hingga per individu. Pada masa itu, masyarakat menganggap bahwa arsip sebagai warisan budaya. Kesadaran tersebut pada akhirnya memunculkan rasa tanggung jawab untuk mengumpulkan dan melestarikan beragam jenis dokumen arsip dari berbagai sektor.

Konsep total archives tidak menekankan pada jenis media yang harus dilestarikan, maka proses pengelolaan arsipnya seharusnya dapat melingkupi berbagai jenis media arsip, termasuk arsip dalam bentuk khusus. Dalam ilmu kearsipan, arsip dengan bentuk khusus ada kalanya diperlakukan sebagai dokumen, misalnya dokumen surat kabar, dokumen karya seni, dokumen poster, termasuk arsip dalam produk dokumentasi budaya yang penting untuk didiseminasikan. Dalam Merriam-Webster online dictionary, etimologi diseminasi berakar pada kata latin disseminatus yang memiliki makna to spread a broad dan to disperse throughout. Secara umum, diseminasi merupakan tindakan pengolahan atau penginovasian pada suatu informasi yang dimiliki individu maupun kelompok yang kemudian hasil pengolahan informasi tersebut disebarluaskan untuk mengugah kesadaran masyarakat, tukar informasi, pemantik inovasi pengolahan informasi, dan lain sebagainya (Toto Widyarsono, 2014). Kaitannya dengan produk dokumentasi budaya, upaya diseminasi merupakan upaya yang bersifat vital sebagai langkah preservasi. Metode diseminasi sesuai dengan perkembangan zaman merupakan langkah praktis namun strategis di banding metode konvensional di era millenium ini. Oleh karena itu penelitian ini berfokus pada diseminasi atau penyebaran produk dokumentasi budaya berbasis internet of things "IOT", melalui website. Situs web merupakan salah satu media untuk menampilkan informasi di internet yang dapat di akses pengunjung dari berbagai tempat dan waktu ynag beramaan (Sumiati dan Rusdin 2012). Website berbasis IOT merupakan salah satu media mutakhir dalam menyebarkan produk dokumentasi budaya di era digital, mengingat zaman yang menuntut segala hal yang tersedia dalam media digital. 
Dalam rangka desiminasi produk dokumentasi budaya berbasis IOT, Departemen Bahasa Seni dan Manajemen Budaya, Sekolah Vokasi UGM telah memiliki website khusus yaitu, "Menara Ilmu Pusat Dokumentais Budaya (PDB)" yang dapat diakses melalui www.pusdok.sv.ugm. Website kanal pengetahuan Menara Ilmu Pusat Dokumentasi Produk Budaya (PDB) ini masih merupakan satu-satunya dan yang pertama di Indonesia dalam upaya pendisemiasian produk dokumentasi budaya dalam tinjauan kearsipan. Karena itulah sudah semestinya laman website ini memiliki eksistensi tersendiri mengingat minimnya upaya pendiseminasian produk dokumentasi budaya berbasis IOT bahkan konvensional sekalipun.

Penelitian ini bertujuan untuk memberikan deskripsi upaya diseminasi produk dokumentasi budaya melalui proyek Menara Ilmu Pusat Dokumentasi Budaya. Berdasarkan hasil penelitian yang sudah dilakukan melalui observasi, diketahui bahwa belum terdapat optimalisasi upaya diseminasi baik berbasis IOT maupun konvensional. Hal ini dibuktikan dengan fakta bahwa terciptanya proyek Menara Ilmu Pusat Dokumentasi Budaya masih merupakan satu-satunya website desiminasi produk dokumentasi budaya dengan latar belakang kearsipan di Indonesia. Hal inilah yang menyebabkan rendahnya tingkat keberhasilan upaya diseminasi terhadap produk dokumentasi budaya. Berdasarkan background tersebut, diperlukan langkah strategis dalam upaya optimalisasi diseminasi produk dokumentasi budaya yaitu melalui proyek Menara Ilmu Pusat Dokumentasi Budaya berbasis IOT dalam bentuk website. Penelitian ini menitik beratkan pada kegiatan diseminasi produk dokumentasi budaya melalu proyek Menra Ilmu Dokumentasi Budaya dan optimalisasinya.

\section{METODE PENELITIAN}

Penelitian ini merupakan penelitian kualitatif deskriptif, dengan menganalisis upaya pendiseminasian produk dokumentasi budaya. Kegiatan penelitian ini dilakukan dengan mengkaji secara langsung kanal Menara Pusat Dokumentasi Budaya, DBSMB, SV UGM Yogyakarta baik secara virtual maupun secara langsung. Penelitian ini dilaksanakan selama satu bulan terhitung mulai Bulan September 2019 sampai November 2019 dengan mengkaji tingkat optimalisasi, kebermanfaatan, dan urgensi dari diseminasi produk dokumentasi budaya melalui Proyek Menara Ilmu Pusat Dokumentasi Budaya. Oleh karena penelitian ini termasuk peneltian kualitatif deskriptif, maka dilakukan empat metode yaitu:

1. Observasi non-partisipasi, yaitu dengan mengamati eksistensi, maupun kebermanfaatan dari adanya Proyek Menara Ilmu Pusat Dokumentasi Budaya dan kemudian menganalisis langkah optimalisasi diseminasinya.

2. Kajian Pustaka, dalam penelitian ini turut mencantumkan berbagai literatur sebagai bahan kajian untuk memperkuat data penelitian yang telah dilakukan.

Alat pengumpulan data yang digunakan dalam penelitian ini adalah kuesioner yang disebar terhadap 100 responden yang berasal dari kalangan masyarakat umum serta civitas akademika. Kuesioner digunakan untuk mengetahui tingkat pengetahuan, kebermanfaatan, urgensi informasi produk dokumentasi budaya, serta tingkat kebermanfaatan website Proyek Menara Ilmu Pusat Dokumentasi Budaya responden. Kuesioner yang digunakan dalam penelitian ini bersifat tertutup. 


\section{HASIL DAN PEMBAHASAN}

Dalam konteks Indonesia, pengarsipan produk budaya belum menjadi program prioritas bagi sebagian besar lembaga kearsipan. Pengarsipan produk budaya justru dirintis oleh kalangan komunitas yang bergerak di bidang seni budaya, salah satunya adalah Yayasan Seni Cemeti (saat ini menjadi Indonesia Visual Arts Archive atau IVAA). Dalam perspektif komunitas seni budaya, pengarsipan budaya menjadi arena politik klaim (Murti, 2014, v), artinya, kesadaran untuk mengarsipkan produk budaya muncul hanya pada saat kasus-kasus klaim warisan budaya. Oleh karena itu, pengarsipan produk budaya kerapkali berhenti pada tahapan penyimpanan tanpa kemudian dilakukan pengkomunikasian atau pendiseminasian. Hal ini pun sejalan dengan masih minimnya kajian mengenai pengarsipan produk budaya. Kajian awal dilakukan Sholikhah dan Rakhmawati (2019) yang menginisiasi upaya penyelamatan arsip seniman dan budayawan melalui suatu integrasi pangkalan data (Sholikhah dan Rakhmawati, 2019, 83). Integrasi pangkalan data seniman dan budayawan dijadikan suatu alternatif solusi mengingat persebaran data seni dan budaya di berbagai pihak, baik pemerintah maupun komunitas, namun validitas, kebaruan, dan kelengkapan data belum dapat dipastikan. Kajian berikutnya menyoroti kerja penyelamatan arsip seniman oleh lembaga kearsipan daerah (Ulvandhia, Rakhmawati, Sholikhah, 2018). Penyelamatan arsip dilakukan melalui aktivitas akuisisi terhadap arsip perseorangan yang dimiliki oleh seniman di wilayah Daerah Istimewa Yogyakarta. Kajian tersebut lebih mengkritisi pada metode akuisisi yang diterapkan oleh lembaga kearsipan daerah dalam menyelamatkan arsip perseorangan yang seharusnya mendapatkan perlakuan yang berbeda dibandingkan arsip-arsip dari institusi resmi pemerintah maupun perusahaan.

Makalah ini menekankan pada proses pendiseminasian produk budaya yang diperlakukan sebagai arsip. Kajian mengenai diseminasi produk budaya sebagai arsip pun masih minim dilakukan, baik oleh akademisi maupun praktisi bidang kearsipan. Kajian diseminasi arsip pertama dilakukan oleh Revano Septian (2018) yang mendeskripsikan kerja diseminasi arsip oleh Indonesia Visual Arts Archive (IVAA) melalui pameran, diskusi, hingga publikasi melalui portal katalog arsip dalam jaringan. Namun demikian, kajian tersebut tidak mengetengahkan dampak dari pendiseminasian arsip terhadap masyarakat. Makalah ini juga mengisi aspek kelemahan dari kajiankajian sebelumnya, yaitu mendeskripsikan dampak dari pendiseminasian produk budaya.

Diseminasi, dalam ilmu kearsipan, termasuk dalam kegiatan program pemasyarakatan arsip. Pederson (1994) dan Bettington (2008) berpendapat bahwa program pemasyarakatan arsip merupakan sekumpulan kegiatan yang ditujukan untuk meningkatkan kesadaran masyarakat tentang arsip dan pengarsipan. Agar tujuan program pemasyarakatan dapat tercapai secara maksimal, maka diperlukan persiapan dan strategi yang matang. Menurut Pederson (1994) ada 5 langkah perencanaan dalam pelaksanaan program pemasyarakatan arsip, yaitu:

1. Menganalisis dan mengevaluasi tujuan dari institusi penyelenggara program pemasyarakatan arsip, dalam hal ini dapat berupa lembaga kearsipan, komunitas 
pengarsipan, museum, maupun lembaga informasi dan dokumentasi lainnya yang memiliki fokus kegiatan pada penyelamatan arsip budaya dan pendiseminasiannya. Maka penyelenggaraan program pemasyarakatan seharusnya mampu meningkatkan pemanfaatan khazanah arsip yang dikelola. Adanya peningkatan pemanfaatan arsip diharapkan mampu meningkatkan kesadaran publik untuk bersedia melestarikan arsip, sesuai standar kearsipan;

2. Menganalisis dan mengevaluasi kebutuhan institusi terhadap program pemasyarakatan arsip, yaitu dengan mensinkronisasi dan menyelaraskan kondisi budaya kerja yang berjalan dengan tujuan penyelenggaraan program pemasyarakatan arsip. Institusi penyelenggara program pemasyarakatan arsip perlu untuk mengevaluasi kegiatan operasional institusi yang dilakukan oleh sumber daya manusianya, mengeliminasi operasional yang bersifat monoton, dan menggantinya dengan aktivitas yang mengarah pada pengembangan program pemasyarakatan arsip;

3. Mengevaluasi dan memetakan kondisi sumber daya, baik sumber daya manusia, keuangan, maupun sarana dan prasarana. Evaluasi dan pemetaan sumber daya diperlukan agar sesuai dengan kebutuhan dan target institusi dalam menyelenggarakan program pemasyarakatan arsip;

4. Memetakan dan menganalisis klien atau pengguna, atau dikenal dengan istilah kajian pengguna. Aspek yang perlu dipetakan dari pengguna, antara lain: karakteristik pengguna berdasarkan latar belakang pendidikan, karakteristik pengguna berdasarkan pada minat terhadap bidang tertentu, karakteristik pengguna berdasarkan usia, karakteristik pengguna berdasarkan kategori arsip yang diakses, dan bagaimana cara pengguna mengisi waktu luangnya. Pemanfaatan kuesioner survey, mengikuti media sosial dan in-depth interview dapat menjadi alternative dalam menganalisis dan memetakan karakter pengguna, terutama pengguna kalangan muda;

5. Mengevaluasi kegiatan atau program sejenis, baik di lingkup internal maupun yang diselenggarakan oleh institusi lain. Hal ini bertujuan untuk menghindari kesamaan karakteristik, meminimalisasi kekurangan dalam penyelenggaraan, hingga peningkatan kualitas luaran program pemasyarakatan arsip yang akan diselenggarakan.

Dalam pelaksanannya, berbagai bentuk program pemasyarakatan arsip menggunakan metode add-on atau istilah mudahnya adalah getok tular. Adapun karakteristik dari metode add-on adalah:

1. Kesuksesan dan pengembangan satu kegiatan program pemasyarakatan bergantung pada keberhasilan kegiatan program pemasyarakatan lainnya, misalnya kesuksesan workshop kearsipan bergantung dari keberhasilan pameran arsip. Maka penyelenggara program pemasyarakatan arsip sebaiknya saling berkoordinasi dan saling mengupayakan agar seluruh bentuk kegiatan yang bertujuan untuk memasyarakatkan kearsipan dapat berjalan baik dan mencapai target maksimal; 
2. Keberhasilan program pemasyarakatan arsip harus berdampak signifikan terhadap pengembangan pemanfaatan, pengguna arsip, hingga kolega institusi melalui beragam kerja sama.

Metode add-on dibagi dalam tiga fase, yaitu:

a. Pendekatan personal, sebelum melakukan pendekatan secara personal, institusi kearsipan perlu memastikan informasi dari arsip, pengelolaannya, hingga penanggung jawab pengelolaan, telah dikemas secara informatif dan menarik. Pengemasan informasi tentunya disesuaikan dengan target pengguna dengan bentuk beragam, seperti berupa brosur atau leaflet, infografis, videografis, media sosial, kolaborasi riset, hingga mengundang individu target sebagai narasumber dari kegiatan diskusi yang diselenggarakan oleh institusi kearsipan.

b. Pendekatan komunitas atau kelompok khusus, tantangan utama dari pendekatan ini adalah kecermatan dalam mengidentifikasi kebutuhan dari suatu komunitas atau kelompok khusus dan mensinkronkan dengan program pemasyarakatan arsip yang dimiliki oleh institusi kearsipan. Adapun bentuk program pemasyarakatan arsip untuk fase pendekatan komunitas atau kelompok dapat berupa workshop, mini-classes, pameran, maupun menjadi relawan membantu institusi kearsipan dalam melestarikan khazanah arsip yang dimiliki.

c. Pendekatan publik atau masyarakat luas, pada fase ini, idealnya, institusi kearsipan telah stabil, baik secara manajerial maupun secara finansial. Kesuksesan pada fase ini dipengaruhi oleh 2 fase sebelumnya.

Dua hal yang perlu diperhatikan dalam mengoperasikan ketiga pendekatan tersebut (Pederson, 1994, 22) adalah:

1. Vertical programming, yaitu memaksimalkan suatu kegiatan dan tidak mengulang kegiatan yang sudah dilaksanakan oleh pihak lain.;

2. Horizontal programming, yaitu menyelenggarakan beberapa kegiatan dalam satu waktu namun tetap pada fokus tema yang sama dan saling berkaitan, misalnya seminar dalam pameran arsip atau workshop dalam rangkaian seminar.

Wujud nyata program pemasyarakatan arsip dapat diklasifikasikan menjadi dua jenis kegiatan utama, yaitu:

1. How-Tos Programs, yaitu sekumpulan kegiatan yang mengajak masyarakat maupun pengguna untuk menciptakan dan melestarikan arsip. Kegiatan yang dikategorikan how-tos programs antara lain:

a. Program pendokumentasian, yaitu sekumpulan kegiatan yang mendekatkan masyarakat untuk mendokumentasikan kegiatan atau peristiwa, misalnya kegiatan proyek sejarah lisan, kelas fotografi, kelas videografi;

b. Pameran arsip, melalui kegiatan pameran, publik dapat berpartisipasi dalam mendiseminasikan arsip yang telah dikelola oleh institusi kearsipan; 


\section{c. Publikasi arsip, dapat berupa brosur, leaflet, guide arsip}

2. Instructional Programs, apabila how-tos programs lebih dispesi ikkan menarget pada individu maupun komunitas atau kelompok khusus, maka instructional programs lebih menyasar kepada masyarakat secara umum. Adapun kegiatan yang dikategorikan sebagai instructional programs diantaranya:
a. Mini-classes
b. Workshop atau seminar
c. Konferensi, baik nasional, regional, maupun internasional
d. Program khusus siswa sekolah maupun mahasiswa, seperti magang maupun relawan
e. Jasa konsultan

Proyek Menara Ilmu Pusat Dokumentasi Budaya (PDB) yang dapat diakses melaluli www.pusdok.sv.ugm merupakan sarana untuk mensyiarkan pengarsipan atau pendokumentasian sebagai suatu ilmu yang dirancang mengunakan media website sesuai perkembangan zaman. Selain itu, PDB pun diperkuat dengan ruang yang memfasilitasi penyimpanan dokumentasi kegiatan atau peristiwa sosial budaya karya mahasiswa, baik berupa arsip sound recording maupun arsip audio visual. Proyek Menara Ilmu Dokumentasi Budaya ini dirancang untuk memenuhi kebutuhan akan transfer informasi yang mengacu pada media komunikasi dan penyebaran informasi mengeai produk dokumentasi budaya serta hasil riset atau produk pembelajaran mahasiswa bidang Kearsipan. Proyek Menara Ilmu Dokumentasi Budaya ini dibuat merujuk pada upaya implementasi dari misi UGM untuk menjalankan pendidikan, penelitian, dan pengabdian kepada masyarakat serta pelestarian dan pengembangan ilmu yang unggul dan bermanfaat bagi masyarakat yang akan berkontribusi pada pembangunan Indonesia. Adanya upaya diseminasi melalui Proyek Menara Ilmu Pusat Dokumentasi Budaya ini, dapat menghidupkan dan mensosialisasikan pentingnya informasi mengenai produk dokumentasi budaya serta arsip, sekaligus sebagai ajang promosi dan memfasilitasi bidang kearsipan agar dengan konsep virtual exhibition (pameran arsip virtual).

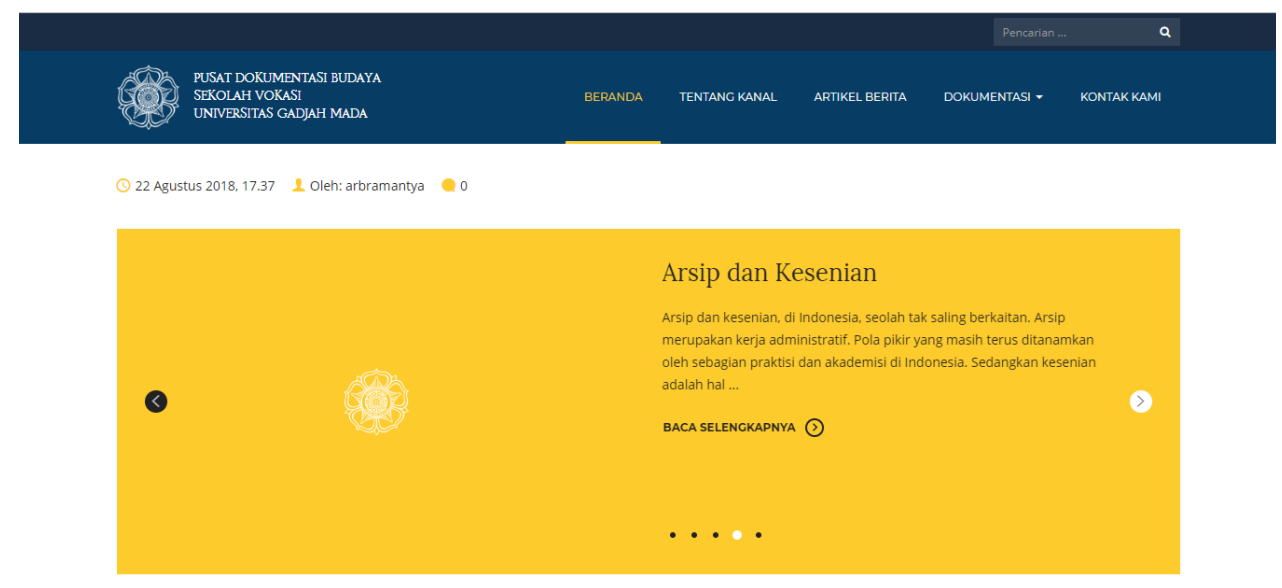

Gambar 1. Tampak Depan Kanal Menara Ilmu Pusat Dokumentasi Budaya 


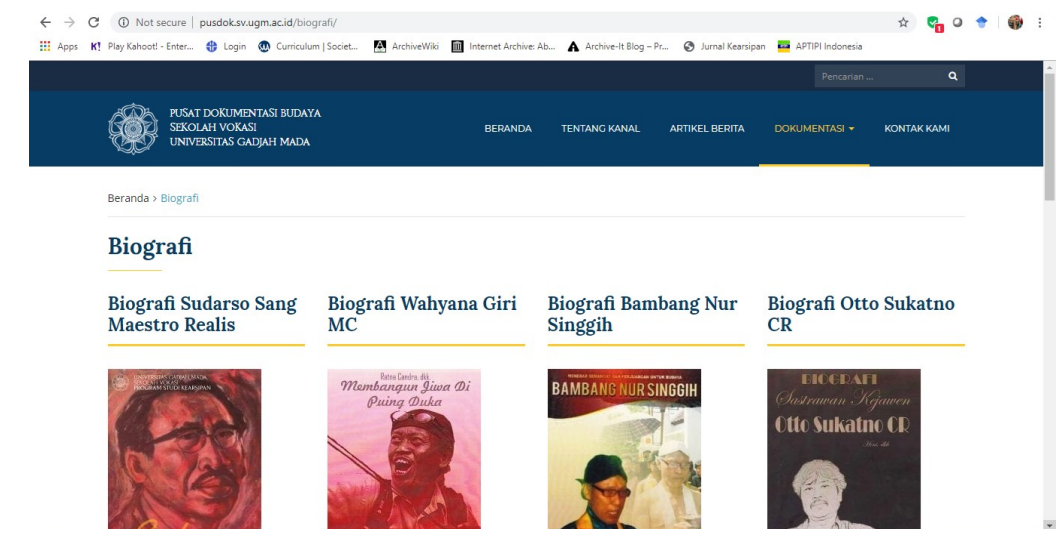

Gambar 2. Produk Biografi Budayawan dan Seniman

Dalam menciptakan optimalisasi diseminasi produk dokumentasi budaya melalui proyek ini, telah dilakukan analisis dari data kuesioner yang telah disebar kepada masyarakat umum, dan civitas akademika dengan jumlah total 100 orang. Berikut ini merupakan hasil penelitian yang diperoleh:

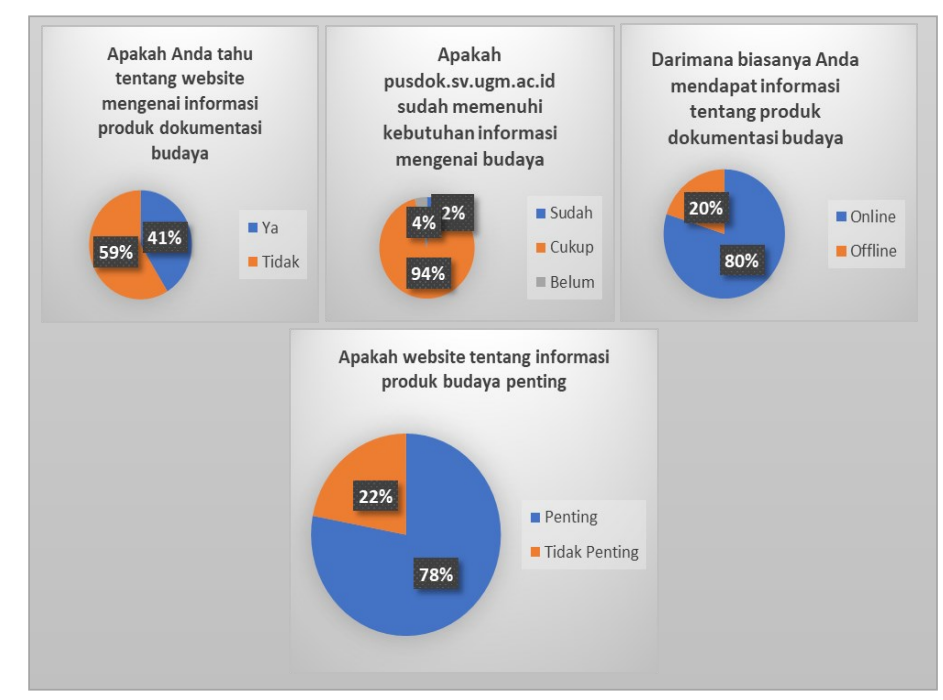

Gambar 3. Hasil Survei

Dari data tersebut, diketahui bahwa:

1. Sebesar $80 \%$ responden mendapat informasi mengenai produk dokumentasi budaya melalui media online (IOT) dan $20 \%$ responden produk dokumentasi budaya secara offline atau konvensional.

2. Sebesar $94 \%$ responden merasa cukup dalam pemenuhan kebutuhan informasi mengenai produk budaya melalui website dokumentasi budaya pusdok.sv.ugm.ac.id, sedangkan terdapat $6 \%$ responden yang merasa kurang dalam hal pemenuhan kebutuhan.

3. Sebanyak 59\% responden belum mengenal dan mengetahui keberasaan website Menara Ilmu Pusat Dokumentasi Budaya.

4. Mayoritas responden yang berjumlah $78 \%$ berpendapat bahwa website yang berisi informasi produk dokumentasi budaya merupakan suatu hal yang penting. 
Dari hasil kuesioner tersebut dapat disimpulkan bahwa, telah terdapat kesaradan yang cukup dari masyarakat umum terlebih lagi civitas akademika mengenai urgensi produk dokumentasi budaya, hanya saja terdapat kekurangan optimalisasi media diseminasi dalam hal publikasi walaupun sudah menggunakan media berbasis IOT yaitu website.

Oleh karena itu, dalam rangka optimalisasi proyek tersebut, penulis memberikan alternatif optimalisasi diseminasi melalui metode publikasi "show ads" dengan sistem partnership baik secara internal dan eksternal. Metode publikasi "show ads" sendiri memanfaatkan teknologi mutakhir yang bisa diakses melalui Google AdSense. Google AdSens merupakan sebuah situs web jaringan google yang melayani iklan teks, gambar, video atau media interaktif yang ditargetkan ke konten audiens dengan sistem operasi cross platform. Melalui Google AdSens inilah metode show ads dapat diaplikasikan secara internal dan eksternal. Berikut ini merupakan konsep pengaplikasian metode publikasi "show ads" dengan sistem partnership baik secara internal dan eksternal:

1. Pengaplikasian metode show ads secara internal

Pengaplikasian metode show ads dengan sistem partnership secara internal dapat dilakukan dengan menjalin kerjasama yang bersifat internal dengan pihak Universitas Gadjah Mada yang meliputi: website resmi UGM, website resmi Kearsipan UGM, dan Website resmi Perpustakaan Pusat UGM

2. Pengaplikasian metode show ads secara eksternal

Pengaplikasian metode show ads dengan sistem partnership secara eksternal dapat dilakukan dengan menjalin kerjasama dengan pihak eksternal yang meliputi: website resmi Arsip Nasional Republik Indonesia, website resmi Perpustakanan Nasional Republik Indonesia dan website yang bersifat edukatif dan sejenisnya.

Berikut ini merupakan mekanisme kerja metode publikasi show ads dengan sistem partnership internal maupun eksternal:

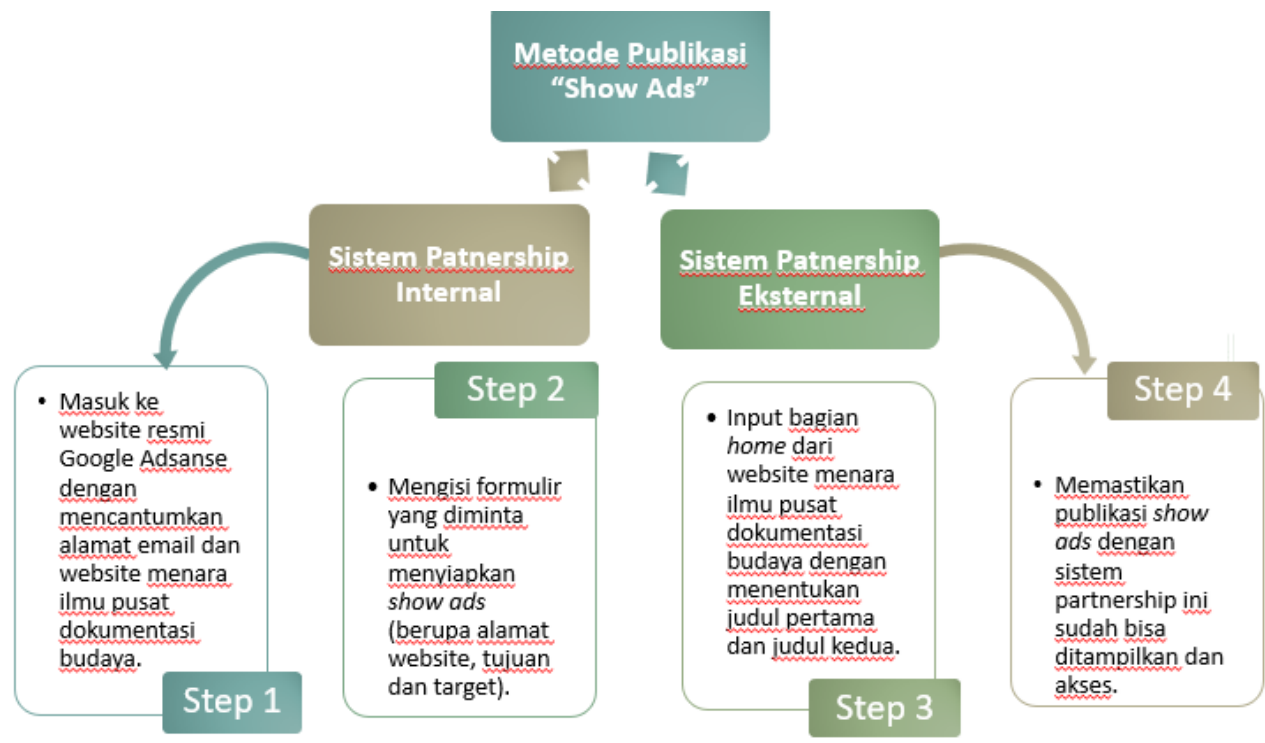

Gambar 2. Produk Biografi Budayawan dan Seniman 
1. Masuk ke website resmi Google Adsanse dengan mencantumkan alamat email dan website menara ilmu pusat dokumentasi budaya

2. Mengisi formulir untuk menyiapkan show ads yang akan ditampilkan yang berupa alamat website, tujuan, dan target (masyarakat umm khsuusnya civitas akademika). Pemilihan kata kunci sebiknya diisi sebanyak mungkin dan secara spesifik.

3. Pada langkah selanjutnya input bagian home dari website menara ilmu pusat dokumentasi budaya dengan menentukan judul pertama sebagai penentu dan judul kedua sebagai tamabahan yang akan ditampilkan di website tujuan.

4. Langkah terakhir yakni memastikan publikasi show ads dengan sistem partnership ini sudah bisa ditampilkan dan akses.

\section{KESIMPULAN}

Disimpulkan bahwa upaya diseminasi produk dokumentasi budaya melalui Proyek Menara Ilmu Pusat Dokumentasi Budaya yang dioptimalkan melalui implementasi "publikasi show ads dengan sistem partnership internal maupun eksternal" merupakan langkah strategis yang dapat menjaga eksistensi, menghidupkan dan mensosialisasikan pentingnya informasi mengenai produk dokumentasi budaya dalam kajian ilmu kearsipan. Selain itu terciptanya proyek tersebut dengan optimalisasinya dapat menjadi ajang promosi dan memfasilitasi bidang kearsipan dengan konsep virtual exhibition sesuai dengan era digital.

\section{DAFTAR PUSTAKA}

Arifin Samsul. 2016. "Kajian Penyelanggara Kebijakan Informasi Publik (Studi Evaluasi Program Diseminasi Informasi di Dishubkominfo Kabupaten Bangkalan Tahun 2013-2015). Thesis Magister Media dan Komunikasi Fakultas Ilmu Sosial dan Ilmu Politik Universitas Airlangga. Surabaya

Fidel, R (2012) Human Information Interaction: An Ecological Approach to Informations Behaviour. The MIT Press

Toto Widyarsono, 2014. Diseminasi Informasi Arsip, Modul I pembelajaran Program Diploma IV Pengelolaan Arsip dan Rekaman Informasi Universitas Terbuka, t.t.

Sumiati dan Rusdin, 2012. Pemanfaatan Situs Web Balai Pengkajian Teknologi Pertanian Sulawesi Tenggara. Jurnal Perpustakaan Pertanian 21 (2): Hal 59-63

Vince Mutiara (2017): Perilaku Pemenuhan Informasi Publik Bagi Masyarakat Kota dan Desa. Jurnal Penelitian Komunikasi Vol. 20 No. 1, Juli 2017:91-106

Undang-undang Nomor 43 Tahun 2009 tentang Kearsipan.

www.pusdok.sv.ugm diakses pada 12 November 2019, pukul 01.36 WIB

Rozaq, Kholid Arif dan Sudjud Dartanto (ed.). (2019). Dunia Koleksi: Hulu Hilir Kepemilikan Karya Seni. Yogyakarta: Ombak

Wardani, Farah dan Yoshi Fajar Kresno Murti. (2014). Arsipelago: Kerja Arsip dan Pengarsipan Seni Budaya di Indonesia. Yogyakarta: Komunitas Bambu

Velin Ulvandhi, Rina Rakhmawati, Faizatush Sholikhah. 2019. "Analisis Penyelamatan 
Arsip Seniman dan Kelompok Seni Melalui Akuisisi Arsip di Dinas Perpustakaan dan Kearsipan Daerah Istimewa Yogyakarta". Jurnal Diplomatika Volume 2 Nomor 2, https://doi.org/10.22146/diplomatika.45900 